\title{
Proceeding
}

8th INSHS International Christmas Sport Scientific Conference, 5-7 December 2013. International Network of Sport and Health

Science. Szombathely, Hungary

\section{Selected somatic parameters by socio-cultural characteristics of czech adult population}

\author{
JAROMIR SEDLACEK , MARTIN SEBERA, JOSEF MICHALEK \\ Faculty of Sport Studies, Masaryk University. Brno, Czech Republic.
}

\begin{abstract}
Sedlacek, J., Sebera, M. \& Michalek, J. (2014). Selected somatic parameters by socio-cultural characteristics of czech adult population. J. Hum. Sport Exerc., 9(Proc1), pp.S311-S318. Results of Czech adult (older than 18 years) population testing are presented. Five somatic parameters were determined: body height $(\mathrm{BH})$, body weight (BW), BMI (BMI), fat tissue percentage (\%FAT), and waist hips rate (WHR), which were measured by machine Inbody 720, with some socio-cultural characteristics. Questionnaires were used to examine parameters of individual sport activity, life status, education level and magnitude of settlement. The presented results show negative trends. All observed parameters seem to be more or less mutually connected. The values of watched characteristics (except $\mathrm{BH}$ ) increase according higher age, both in groups of males and of females, too. Parameter BH shows that secular trend in Czech population continues, when younger generations are taller like olders. Majority of adult Czech population does not practice any sport activity. This prevailing inactivity of the population influenced negatively our watched somatic paramaters. Those individuals who are single or possess good education levels, have better results in all observed parameters. Magnitude of settlement determines only slight differences in these watched parameters. These results are part of The project "Creating a research team for the purpose of determining the level of physical activity (inactivity) in selected age groups of the population of men and women in the Czech Republic" (CZ.1.07/2.3.00/20.0044) and is financed by the European Social Fund and the state budget of the Czech Republic. Key words: CZECH ADULTS, SOMATIC, SOCIO-CULTURAL, EDUCATION, SPORT ACTIVITY.
\end{abstract}

Corresponding author. Faculty of Sport Studies, Masaryk University. Brno, Czech Republic.

E-mail: jaromir.sedlacek47@gmail.com

8th INSHS International Christmas Sport Scientific Conference, 5-7 December 2013. International Network of Sport and Health Science. Szombathely, Hungary.

JOURNAL OF HUMAN SPORT \& EXERCISE ISSN 1988-5202

(c) Faculty of Education. University of Alicante

doi:10.14198/jhse.2014.9.Proc1.14 


\section{INTRODUCTION}

Recreational movement activities play at present sedentary way of life more and more important role. There is shown that lack of movement activity leads to lowering of physical fitness, this is parallel manifested by negative trends in somatic parameters (Cacek, 2012; Kunesova, 2006); this of course very often negatively influences the quality of individual life (Sedlacek, 2007). Socio-demographic analysis shows that quantity and also the quality (intensity) of sport activity among adult population are insufficient as a whole. It was shown (Eurobarometer, 2004) that adult men exercise more than women. In 2004 41\% of men claimed that they play sport at least once a week, but women stated only $35 \%$. Regarding age the situation shows that frequency decreases as the age category rises; from $60 \%$ in age $15-24$ years it falls to $28 \%$ in age over 55 years. The volume of sports practice is influenced with the level of education and with the socio-cultural status, too. In Europe neither the fee nor the lack of facilities prevents people from doing some sports activity. It is more due to the constraints of the typical way of life in modern society (lack of time due to professional activities or family responsibilities), which discourage citizens of the Union from playing sports on a regular basis. Generally a strong majority of citizens in the European Union cite the improvement of health as being the principal benefit of sport (78\%). It shows the good level of education in the field of positive influence of sport and movement activities as a benefit to one's physical and mental health and for remaining active life. Other reasons for sport practicing are the development of physical performance $(46 \%)$, relaxation (43\%), having fun (39\%) and fact of being with friends $(31 \%)$.

In adult Czech Republic population is prevailing overweight and obesity. Near $52 \%$ of adult Czech population have BMl over normal values (Cacek, 2012). From it is $35 \%$ overweight and $17 \%$ is in the category obesity. Difference from last researches (6 years) is plus 3\% more with overweight. To this great population overweight contribute more often men and older people. In general the time devoted by population to physical activity has been shortened. Czech population daily walks about 1 hour and 30 minutes in slower speed, 1 hour and 5 minutes devotes house works (Kunesova, 2006).

\section{MATERIAL AND METHODS}

In this article are presented results of Czech adult (older than 18 years) population. There are involved 1440 individuals, from who are 666 males and 774 females. Five somatic parameters were determined> body height $(\mathrm{BH})$, body weight $(\mathrm{BW})$, BMI $(\mathrm{BMI})$, fat percentage \%FAT and waist hip rate (WHR), which were measured by apparatus Inbody 720 . Sport activity (A - yes or B - not) and some socio-cultural aspects were learned by questionnaire. In this contribution we watch determination of answers on questions about magnitude of settlement (A: <999, B: 1000 - 29999, C: 30000 - 99999, D: >100000), life status ( $A$ : single $-B$ : married - C: divorced - D: widowed -E: registered partnership) and education level (A: none education -B: fundamental -C: trainee -D: GCE exam -E: university) on somatic parameters. Situations are shown by graphs and are described. Differences of groups were evaluated on $5 \%$ statistical significance level. Fundamental statistical data can be seen in Table 1.

Table 1. Fundamental statistical data of sport activity and somatic parameters

\begin{tabular}{|l|l|l|l|l|l|l|l|}
\hline Sex & Sport act. & N & BH $(\mathrm{cm})$ & BW $(\mathrm{kg})$ & BMI (1) & $\%$ FAT & WHR \\
\hline Male & Yes & $233 / 35 \%$ & 180.1 & 81.6 & 25.1 & 16.4 & 0.88 \\
\hline Male & Not & $433 / 65 \%$ & 178.8 & 84.0 & 26.5 & 20.0 & 0.90 \\
\hline Female & Yes & $226 / 29 \%$ & 166.9 & 66.4 & 23.8 & 27.2 & 0.86 \\
\hline Female & Not & $548 / 71 \%$ & 166.2 & 66.8 & 24.2 & 29.4 & 0.86 \\
\hline Totaly & - & $1440 / 32 \%$ & 172.4 & 74.4 & 25.02 & 24.1 & 0.79 \\
\hline
\end{tabular}




\section{RESULTS}

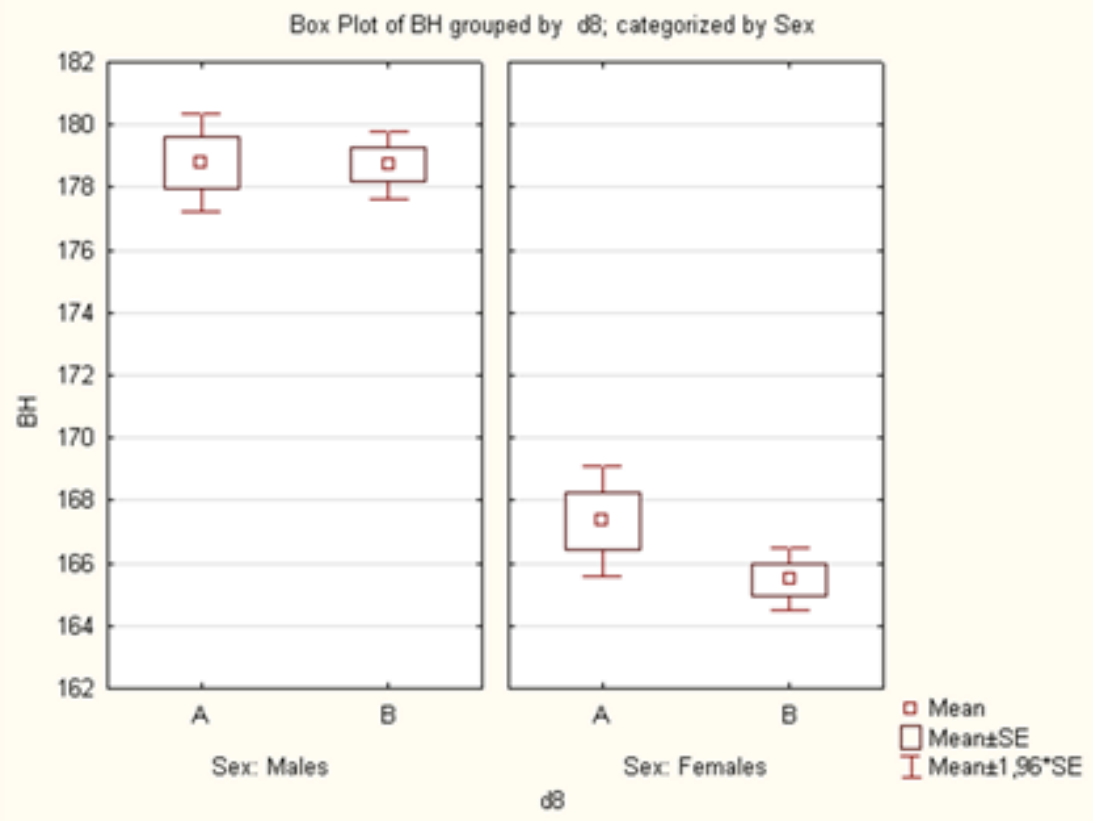

Figure 1. BH Differences in question "do you practice regularly sport" Yes (A)-No (B)

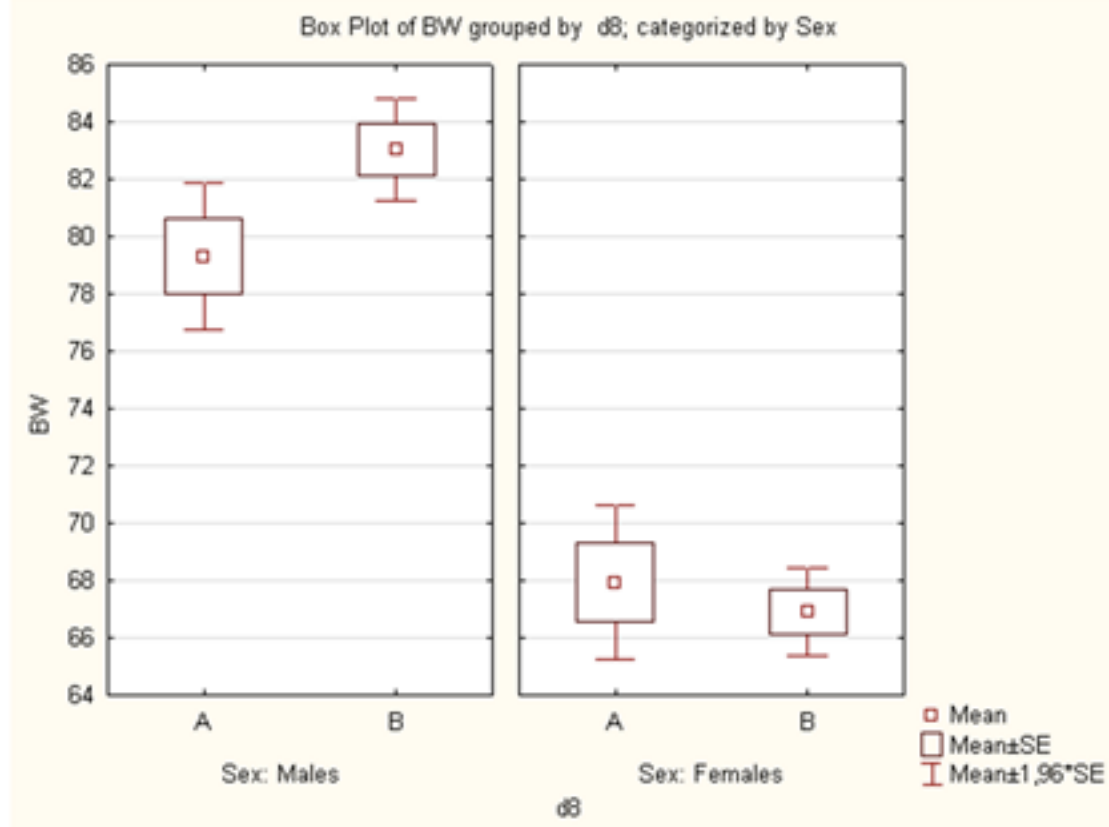

Figure 2. BW differences in question "do you practice regularly sport"? Yes (A)-No (B) 


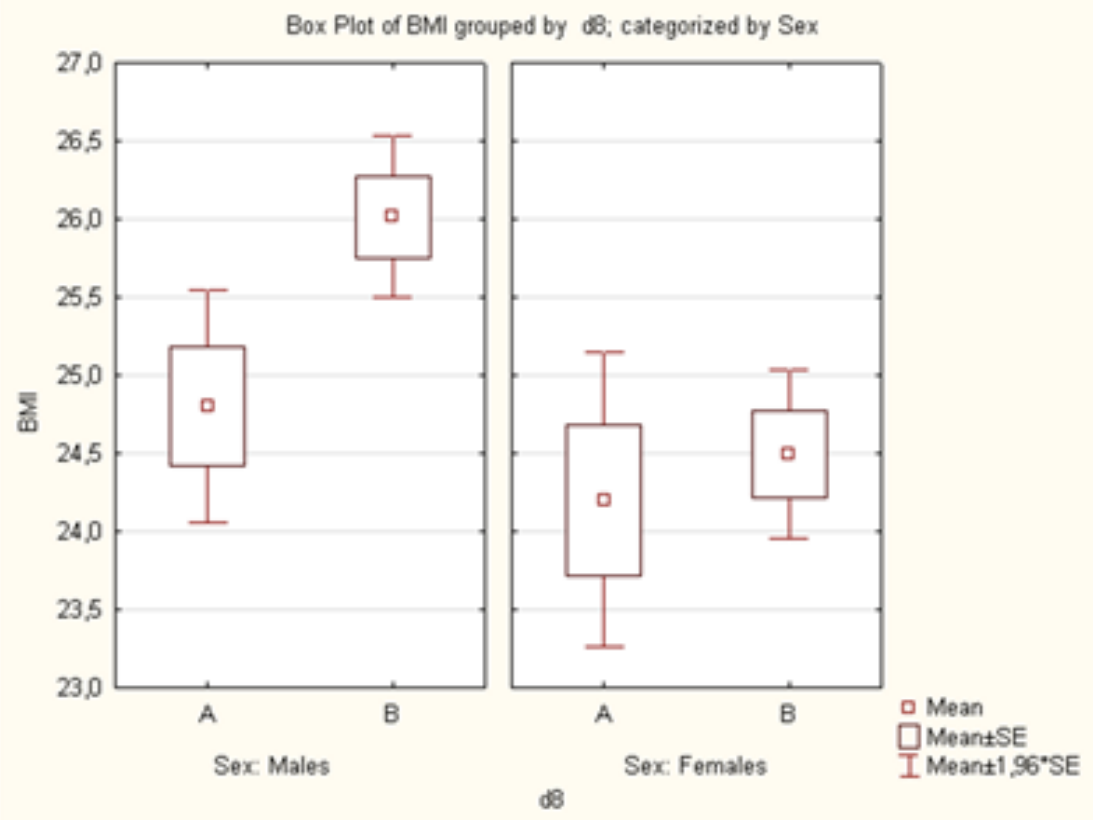

Figure 3. BMI differences in question "do you practice regularly sport"? Yes (A)- No (B)

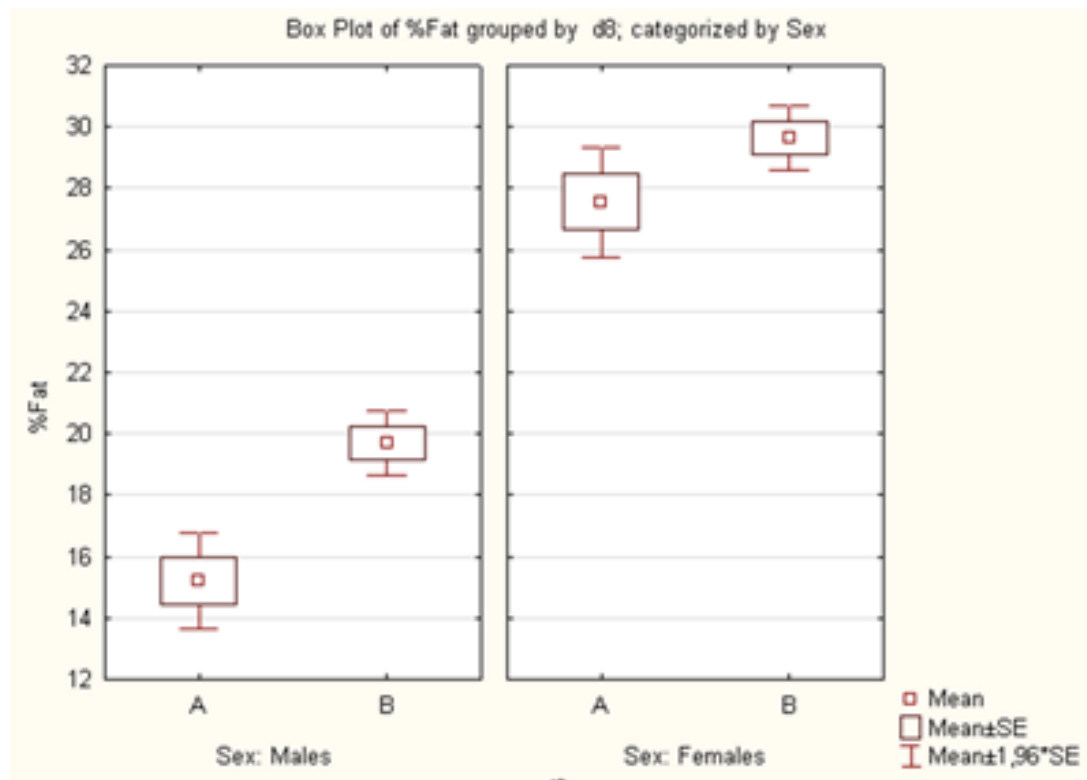

Figure 4. \%FAT differences in question "do you practice regularly sport"? Yes(A)- No(B) 


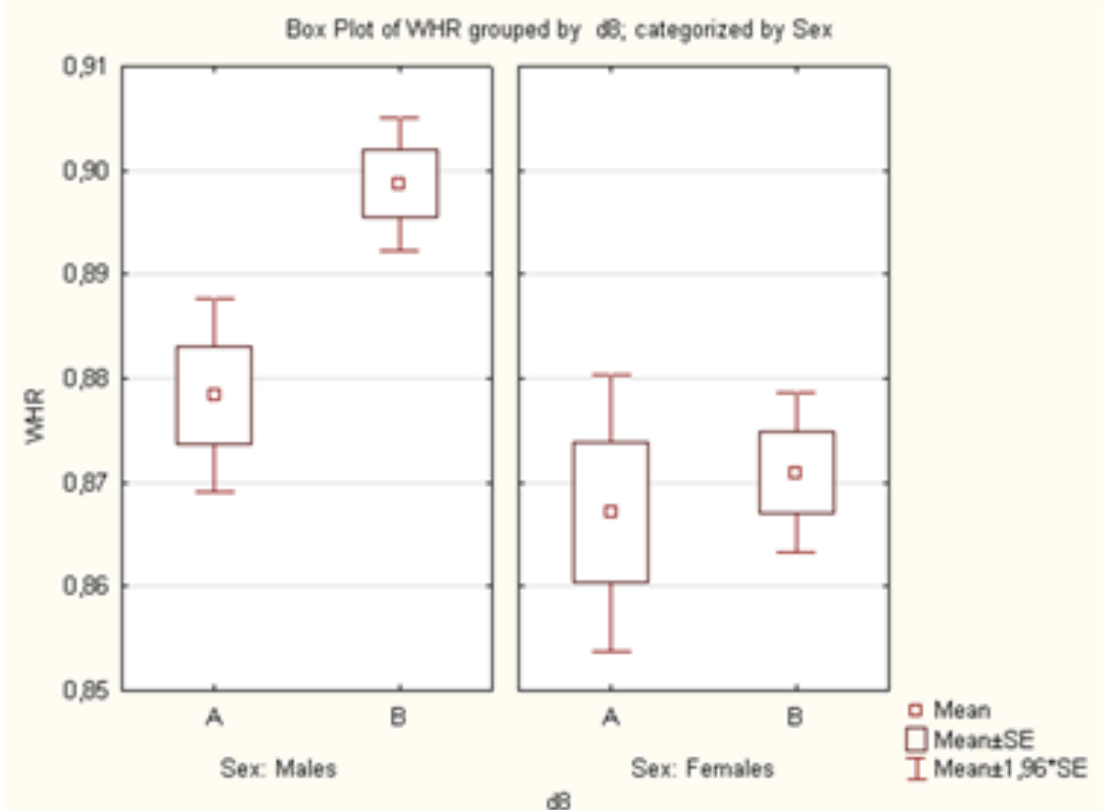

Figure 5. WHR differences in question "do you practise regularly sport"? Yes (A)- No (B)

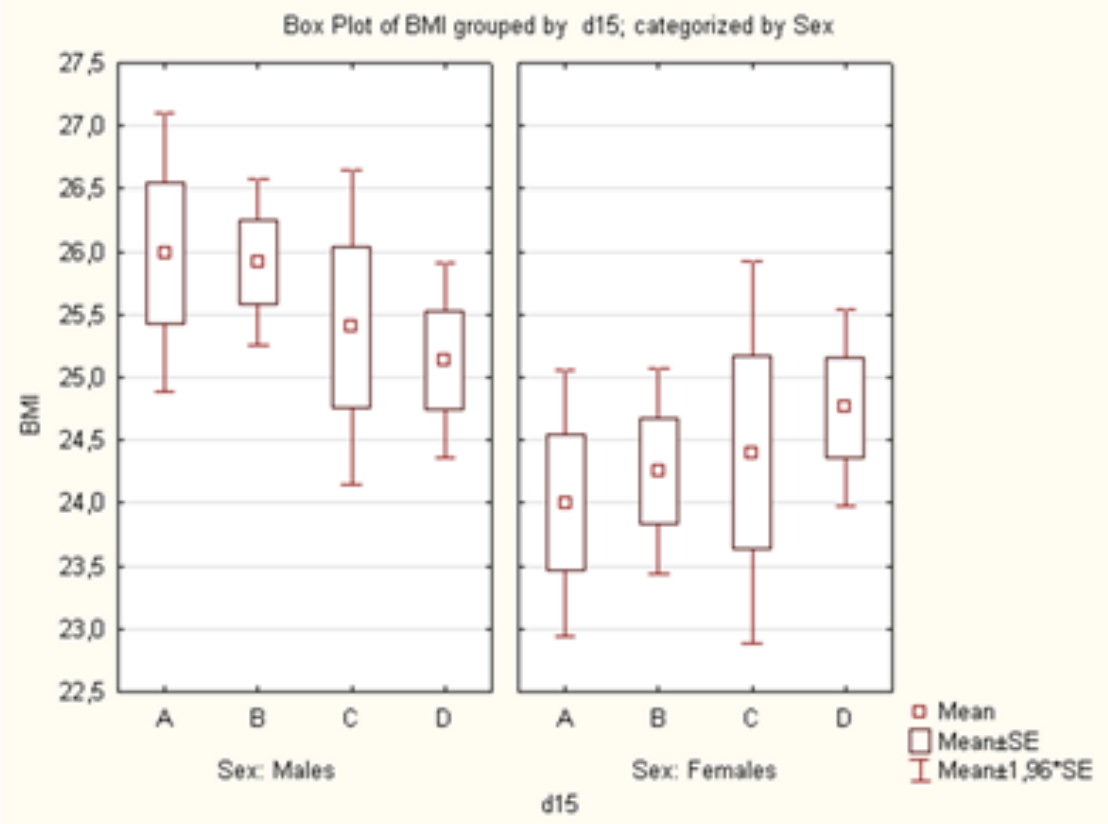

Figure 6. BMI differences according magnitude of settlement: < 999 (A), 1000 - 29999 (B), 30000 - 99999 (D), $>100000$ (D) 


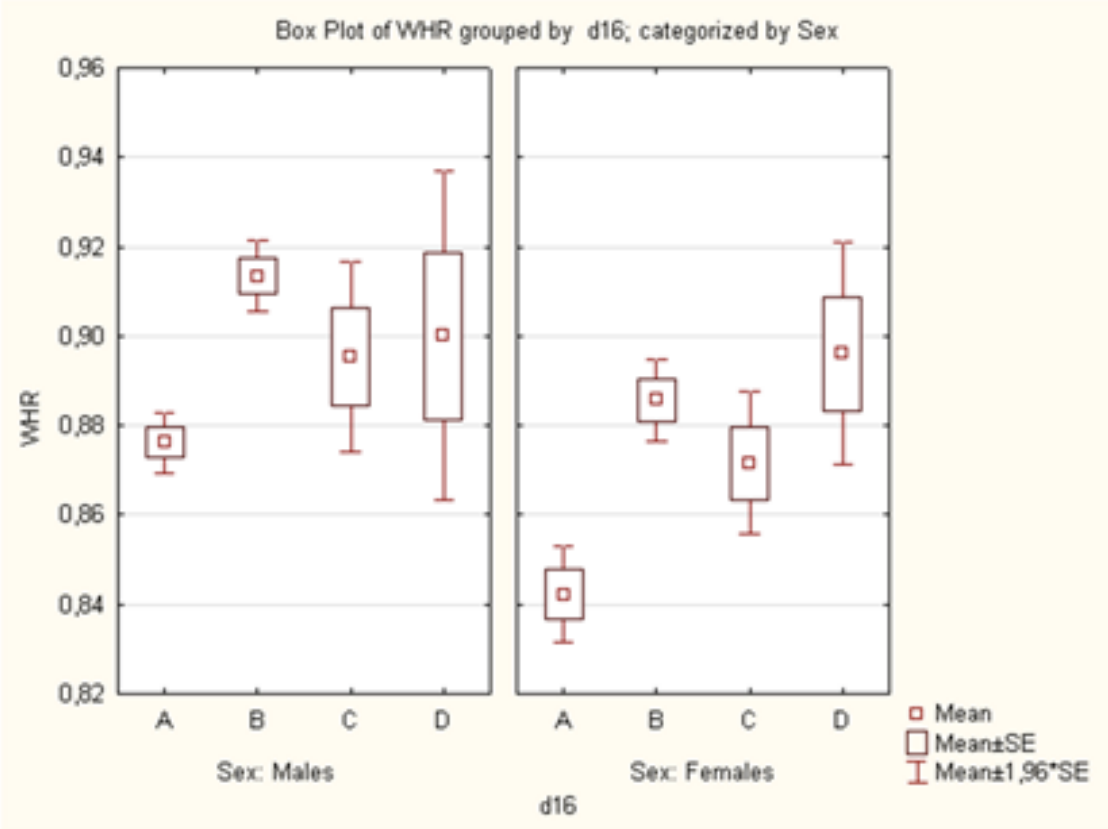

Figure 7. WHR differences according living status: sigle (A) - married (B) - divorced (C) - widowed (D) registered partnership (none answer)

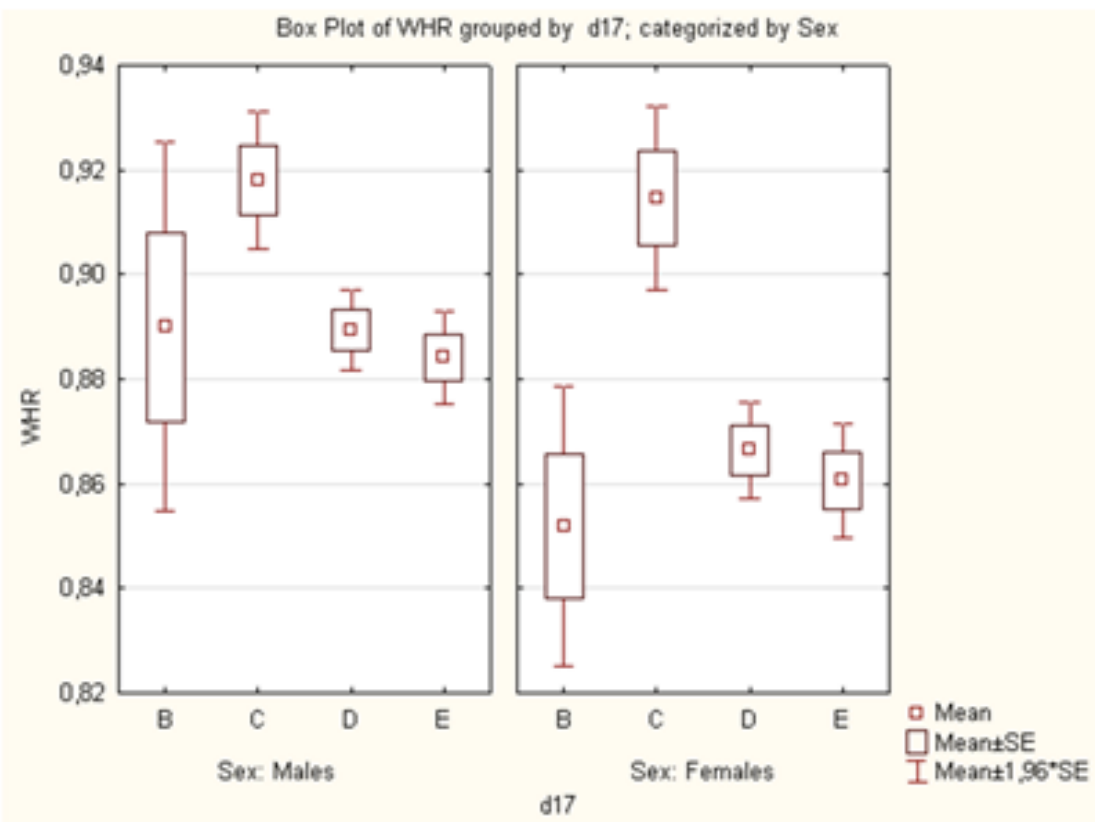

Figure 8. WHR differences according aducation level: none education (none answer) - fundamental (B) trainee (C) - GCE exam (D) - university $(E)$ 


\section{DISCUSSION}

Comparison of watched somatic parameters of those who practice sport regularly or not can be seen on fig $1-5$. In parameter BH are differences between those who practice and do not practice sport in groups of males and females very small. Both groups of males (sport practicing $x$ not practicing) have near the same $\mathrm{BW}$, while between females groups is small difference; group of sport practicing is slightly taller, though the difference is not statistically significant. In parameter BW we can see vice versa situation; males who did not practice sport have significantly higher BW. Groups of females have near the same BW. In groups of males there are all other 3 watched parameters (MBI, \%FAT and WHR) significantly different between those who practice sport and those who do not practice. In all these parameters is group of not practicing sport over normal (recommended) values, while values of groups of sport practicing are in the reference interval, though the average value is near the upper border of this interval. In groups of females are these 3 parameters different like it is among males. Of course group of not practicing sport regularly possesses slightly higher average values. When we compare males with them we must stay that females are not so much beyond recommended values, even in the group of not practicing sport. As a second the differences of females between sport practicing and not practicing are not so clear like it is between groups of males; we did not find statistically significant differences. In parameter \%FAT (fig 4) can be seen relatively greatest difference, but again not statistically significant. We can deduce when we also see parameters BMI and WHR that fat tissue is in the groups of females distributed more regularly in the whole body, like it is in groups of males, where is fat tissue cumulated mostly around body waist (fig 5).

Magnitude of settlement influences our watched somatic parameters in the opposite direction between males and females (fig 6 ). In groups of males there possess the greatest values males staying in villages and small towns. The greater the town is, the lower average value of i.e. parameter BMI the males have. There is a significant difference between villages and small towns to great towns inhabitants. In groups of females the tendencies are opposed. The best average values of BMI are in villages and with the lager magnitude of settlement the BMI values are getting higher. Statistical significant value was found between females from small villages and great towns. In spite of opposed tendencies of BMI, BW, \%FAT and WHR between males and females, there are all average values in groups of males out of recommended intervals, while in female groups are inside them.

Living status also influence all watched parameters, except BH. On the fig 7 there can be seen values of WHR. In groups of males and females, too there is evident, that singles possess the better values. At moment of getting married the values raise dramatically. Possible divorce or getting widow can course only small changes. There are statistically significant differences between groups of singles and all other groups, both in males and females. In this case it should be mentioned that those singles are the youngest; it supports previous statements that the youngest possess significantly better values of our watched somatic parameters.

Level of education also influences our watched parameters (again except BH). On the fig 8 there can be seen great differences between those who qualification is trainee and all others groups, both males and females; they are statistically significant. As a whole female groups (except group of trainees) possess slightly better results like male groups. 


\section{CONCLUSIONS}

1. This research shows that Czech adult population do not practice sport in adequate quantity. Those who practice sports possess better somatic parameters (except body height) like those who do not practice sport regularly.

2. In spite of males practising sports more often like females, they possess far worse values of our watched somatic parameters; again except parameter body height. Most of these parameters are in male groups over recommended values.

3. Magnitude of settlement influences our watched somatic parameters in the opposite direction between males and females. In villages and small towns possess males the worst values, while females just here possess the best values.

4. Living status influences 4 of our watched parameters (BW, BMI, \%FAT and WHR). Significantly best results possess singles whose we can also logically consider as the youngest, both in groups of males and females.

5. Watched somatic parameters (again except $\mathrm{BH}$ ) are also determined with the level of education. Those who are trainees possess statistically significant worse values with regard to other levels of education. It seems that the higher the level of education is, the more often is the sport practice performed.

\section{REFERENCES}

1. Cacek, J. et al. (2012). Obesity as an indicator of fitness of different age groups of men of the Czech Republic. Gymnasium, 13(2), pp.78-84.

2. Eurobarometer 213. (2004). The citizens of the European Union and Sport. Special edition, November, pp.49.

3. Kunesová, M. (2006). Životní styl a obezita- longitudinální epidemiologická studie prevalence obezity $\vee \check{C} R($ Living style and obesity - longitudinal epidemiology study of obesity prevalence in Czech Republic). Česká lékařská společnost ČSL JEP, Česká obezitologická společnost (Life style and obesity - longitudinal epidemiologic study of obesity prevalence in Czech Republic). Stem/Mark, a.s. Praha.

4. Sedlacek, J. et al. (2007). Kondičná atletická príprava a rekreačná atletika (Condition athletic preparation and recreative athletic). Univerzita Komenského Bratislava.

\section{Appendix}

The project "Creating a research team for the purpose of determining the level of physical activity (inactivity) in selected age groups of the population of men and women in the Czech Republic" (CZ.1.07/2.3.00/20.0044) is financed by the European Social Fund and the state budget of the Czech Republic. 